
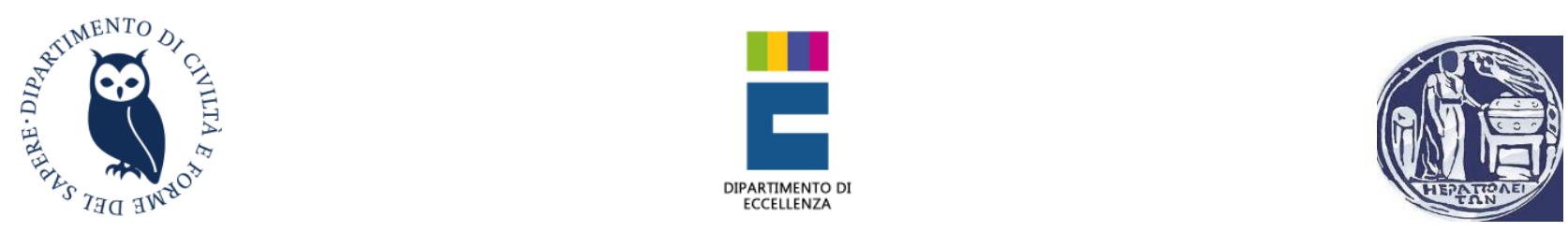

\title{
New research in the Northern necropolis of Hierapolis, Phrygia (Turkey)
}

\author{
Anna Anguissola, Silvana Costa, Antonio Monticolo \\ University of Pisa \\ Italian Archaeological Mission at Hierapolis
}

Since 1988, Hierapolis of Phrygia has been included in UNESCO's list of mixed natural and cultural world heritage sites. Hierapolis is situated on a calcareous platform some 350 metres above sea level, on the western brink of the Anatolian plateau. It covers an area of ca. 65 ha and is surrounded by large cemeteries, built throughout the Hellenistic and imperial Roman periods. Some $\mathbf{6 0 0}$ monumental tombs with a remarkable variety of architectural types have been identified. Only a few of them have been either excavated or presented in scholarly publications.

\section{The project}

This project (2017-2020) is the first coordinated effort to examine the funerary landscape of Hierapolis from a historical and social perspective. Our research focuses on the largest and the most complex of the cemeteries at Hierapolis, the northern Necropolis. Firstly, we aim to account for the general layout of the burial ground, as related to its topography, organizing principles, access and circulation, continuity and changes. Secondly, we wish to assess how individual monuments and sarcophagi contributed to the articulation of the funerary space by focusing on aspects such as material, techniques, visibility, use, and ownership of these objects. Thirdly, we integrate the study of funerary inscriptions as a means to gather information not only on specific persons, their status and lineage, but also on systems of belief, social symbols, memory, identity, social and political organization.

\section{Area and funerary typologies}

We focus on the area between Tombs 156 and 162, including some 20 monuments and dozens of sarcophagi along the main road to Tripolis on the Meander. The buildings are arranged on a system of terraces on the hill. All the building typologies attested in Hierapolis between the Hellenistic period and the 4th century CE are clustered here: tumuli with vaulted chambers, pedestal buildings or platforms supporting sarcophagi, funerary enclosures, and burial chambers covered by saddle or barrel-vaulted roofs. Both marble and 
travertine sarcophagi and a large corpus of inscriptions, often preserved in their original archaeological context, contribute to a nuanced picture that is seldom available in ancient cemeteries. The criteria that we are developing to gather and examine the evidence from Hierapolis may offer valuable instruments to approach both entire cemeteries elsewhere and individual monuments without a comparable archaeological context.

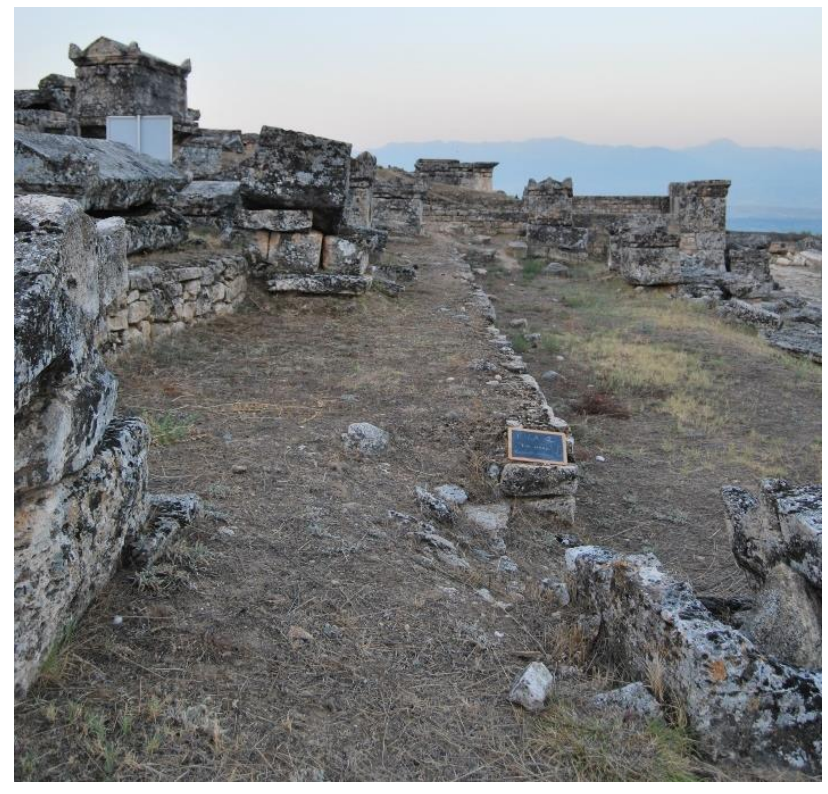

Terraces near Tomb 163d

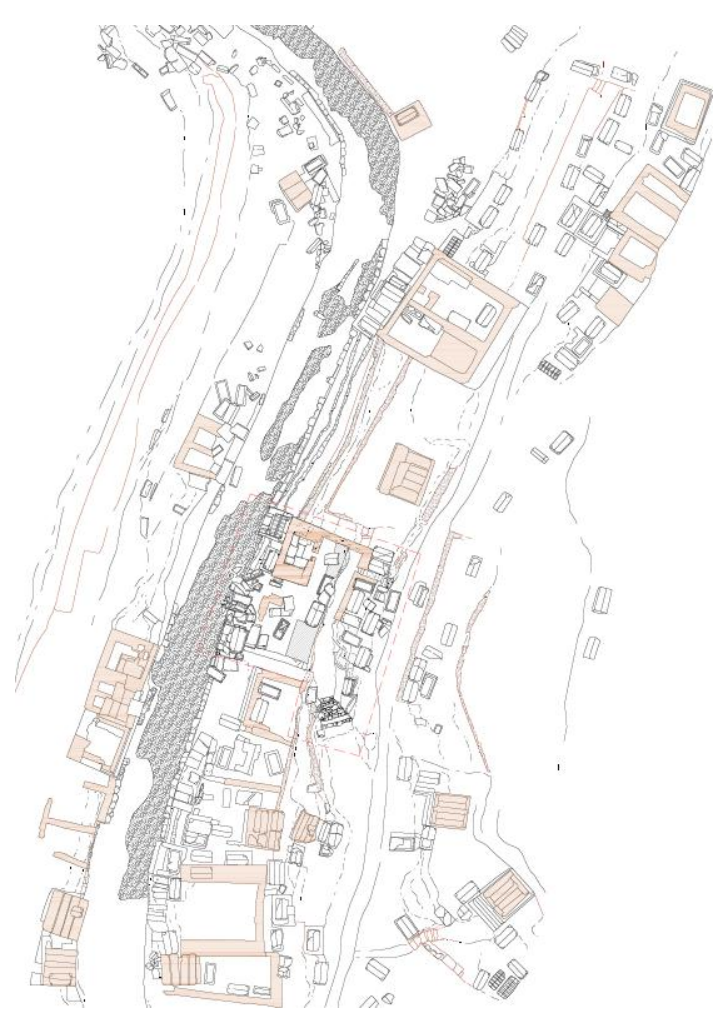

Area of the Tombs 156-162, 1:100

\section{The case study (Tomb 159c)}

An imposing funerary chamber, originally covered by a barrel vault, stands at the north end of the area included in the enclosure. Two sarcophagi to the east of the enclosure bear lengthy Greek inscriptions, dating to the $3 \mathrm{rd}$ and the 4 th centuries CE respectively. They explain that an area of $15 \times 6$ cubiti (which is significantly smaller than the entire Tomb 159c), as well as some of the sarcophagi placed in the tomb and the heroon (i.e., a monumental grave) "to the left of those who enter the enclosure" belonged first to a man named Marcus Aurelius Rouphos Asklepianos, and later to the deacon Theodoros. Excavations revealed the previously undetected remains of a second, smaller chamber that once stood in the southern part of the enclosure. The presence of a smaller chamber, which may have belonged to a different individual or family, would explain the need to describe explicitly the size and location of the grave. Perhaps, most of the openair area and the smaller chamber belonged in the 4th century CE to Fl. Philippos, whose name was inscribed 
above the entrance. It is impossible to determine whether Tomb 159c was first built during the 3rd century $\mathrm{CE}$, when the earliest of the two inscribed sarcophagi must have been placed inside the enclosure. However, this large complex altered significantly the existing layout of the necropolis, blocking direct circulation from the main street to the upper terrace of the necropolis, previously reached thanks to large stairs. A further, relevant moment in the life of Tomb 159c is the progressive occupation of the public soil in front of the funerary buildings in the first row. The burial ground seems to have grown at an impressively fast pace, to the point that it became virtually impossible to enforce orderly planning and the respect of public and private property.
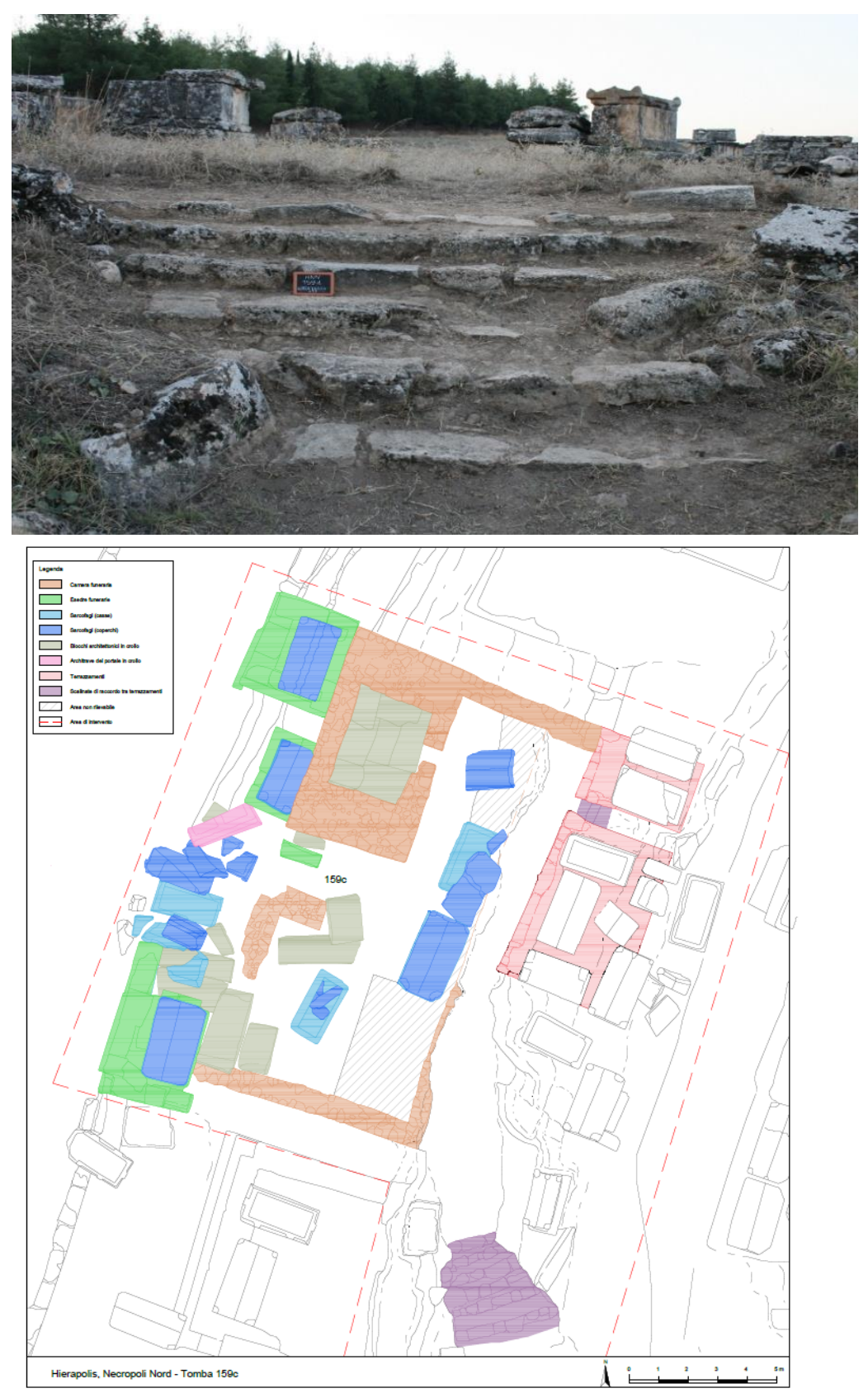

(above) View of Tomb 159c from the upper terrace (N-E corner)

(below) Plan of Tomb 159c with detail of the structures, 1:50 (S. Costa) 


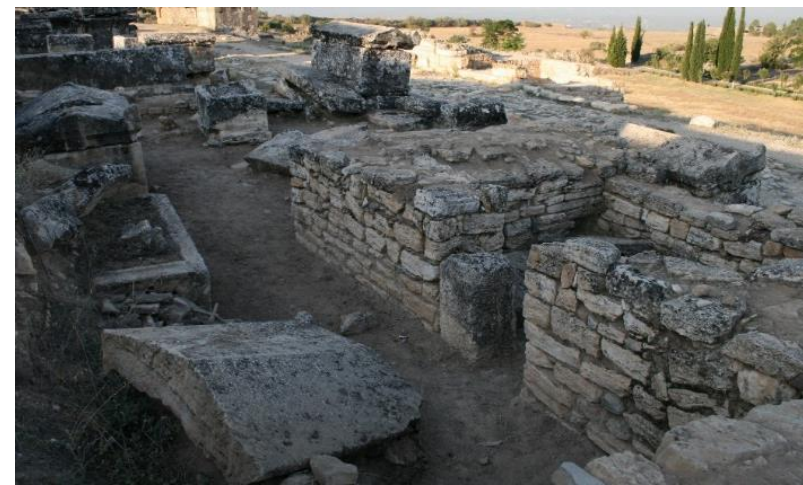

Walls of the smaller chamber of Tomb 159c

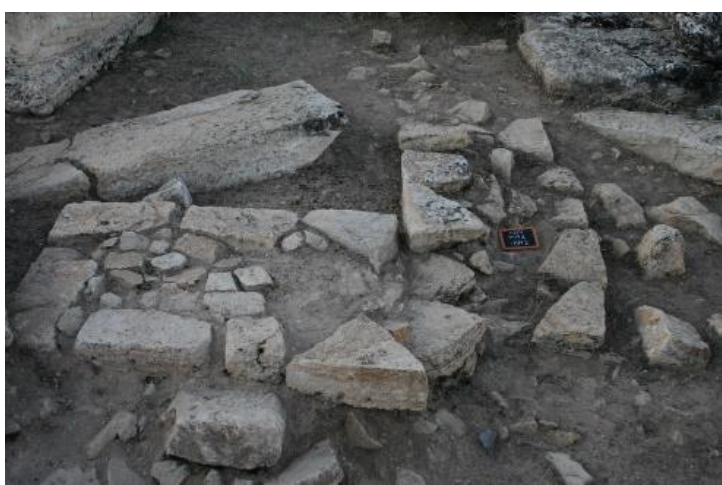

Stairs to the upper terrace

\section{References:}

Anguissola, A., Costa, S. (2020). I sarcofagi della necropoli Nord di Hierapolis in contesto. Studi Classici e Orientali, 66, 301-328

Anguissola, A. (forthcoming). Nuovi dati per la conoscenza dei paesaggi funerari di Hierapolis di Frigia. Agoge, 14-16

Anguissola, A., Costa, S., Monticolo, A. (forthcoming). Ricerche nella necropoli Nord a Hierapolis di Frigia. ArcheoLogica Data, 1

This project is conducted within the framework of the Italian Archaeological Mission at Hierapolis (MAIER) and has been generously supported since 2016 by the Italian Ministry for University of Research through the funding scheme for Research Projects of National Interest (PRIN 2015) and by the University of Pisa (Dipartimento di Eccellenza 2018-2023).

For further information, please contact: ant.monticolo@gmail.com 